\title{
Innovative Technologies for Sustainable Passenger Transport
}

\author{
Ondrej Stopka $\left(\mathbb{D},{ }^{1}\right.$ Vladislav Zitricky, ${ }^{2}$ Borna Abramovic $\mathbb{D}^{3}{ }^{3}$ \\ Marin Marinov, ${ }^{4}$ and Stefano Ricci ${ }^{5}$ \\ ${ }^{1}$ Institute of Technology and Business in Ceske Budejovice, Ceske Budejovice, Czech Republic \\ ${ }^{2}$ University of Zilina, Zilina, Slovakia \\ ${ }^{3}$ University of Zagreb, Zagreb, Croatia \\ ${ }^{4} \mathrm{New}$ Castle University, Tyne, UK \\ ${ }^{5}$ Sapienza University of Rome, Rome, Italy
}

Correspondence should be addressed to Ondrej Stopka; stopka@mail.vstecb.cz

Received 9 December 2018; Accepted 23 April 2019; Published 20 May 2019

Copyright (c) 2019 Ondrej Stopka et al. This is an open access article distributed under the Creative Commons Attribution License, which permits unrestricted use, distribution, and reproduction in any medium, provided the original work is properly cited.

Functional transport systems represent an important place in terms of the population mobility and generate a prerequisite for the economic-related development among individual regions. Population mobility increase in recent decades also pushes a question regarding the sustainable development of various world economies. However, a growing need to travel brings negative environmental impacts and points to the necessity for environmental protection. Technological premise creates the prerequisites for organizing, operating, and managing traffic and transport with as little negative environmental impacts as possible and helps to create a system of sustainable mobility. An option to develop transport systems consists in the implementation of innovative technological solutions applied within passenger transport processes.

For a successful transport process optimization and its consequent execution, it is necessary to define individual activities needed to carry out the entire process. Activities can be divided into individual levels, whereby the better orientation in the process can be achieved. In order to efficiently optimize individual activities within transport processes, operations research methods and information technologies can be applied. The current problem is to solve the sustainability of technological developments in assuring the quality of life for future generations. Trend of innovate and smart technologies does not eliminate transport and its processes from the problem of sustainability. The question of these days is whether the introduction of innovative and smart technologies can guarantee the sustainability of transport processes also for the future.

In the presented special issue, lead guest editors received 17 manuscripts of research articles. In total, 7 articles (86 pages) out of 17 have been successfully reviewed by the reviewers and subsequently published.

The article entitled "Research of the Passenger's Preferences and Requirements for the Travel Companion Application" deals with a research of the passenger's preferences and requirements for the travel companion. The research study consists of four steps based on analyses of interaction points, interviews, and workshops. Each step of the proposed methodology brings interesting feedback on the design and functionality of the travel companion. The paper is based on particular results of the "H2020 project - 730842 Governance of the Interoperability Framework for Rail and Intermodal Mobility (GoF4R)".

The article "Challenges for Air Transport Providers in Czech Republic and Poland" brings the readers an insight into the elements of demand placed within air transport, particularly possibilities of increasing the demand for air transport in Central Europe, especially in the Czech Republic and Poland.

The article "Urban Transformation in the Context of Rail Transport Development: The Case of a Newly Built Railway Line in Gdańsk (Poland)" discusses the mutual relationships among operation of a newly built railway line and spatial changes taking place in its closest vicinity which determine 
the accessibility to it. The proposed research methods, within this research study, include the GIS tools, direct measurements of passenger exchange, and public opinion poll among the passengers taking the new line. The city of Gdańsk in Poland was considered the research area.

The article "Approach to the Weight Estimation in the Conceptual Design of Hybrid-Electric-Powered Unconventional Regional Aircraft" is focused on the development of an innovative approach to the weight estimation in the conceptual design of the Hybrid-Electric-Powered (HEP) Blended Wing Body (BWB) commercial aircraft. The research within this article explores the potentialities of an energy-based approach for the initial sizing of HEP unconventional aircraft in the early conceptual phase of the design. A detailed parametric analysis has been carried out to emphasize how payload, range, and degree of hybridization are strictly connected in terms of feasible mission requirements and related to the reasonable expectations of development of electric components suitable for aeronautical applications.

The article "Aspects of Improvement in Exploitation Process of Passenger Means of Transport" is oriented toward analyzing and evaluating the system of exploitation of passenger transport means and proposing solutions for its improvement. Based on the theory of exploitation systems, quantitative utilitarian models have been built, which have been verified by applications using data obtained from Municipal Communication Company (MPK) in Wroclaw. Originality and innovation in the recognition of this research problem consist in applying the analysis and evaluation of the Ishikawa diagram exploitation system, Pareto-Lorenzo analysis, and FMEA (Failure Mode and Effects Analysis) methods. On the other hand, a QFD (Quality Function Deployment) diagram was used to build a model of improvement of the exploitation system, with the use of which the target values of parameters for the operation of MPK passenger transport in Wroclaw were determined. The applied methods and research techniques are rarely used in the field of testing of vehicle operation systems.

The article "Theoretical Comparison of the Effects of Different Traffic Conditions on Urban Road Traffic Noise" investigates the effect of different traffic conditions on urban road traffic noise. The results of this research study showed that traffic congestion had considerably the maximum peak compared to other traffic conditions which would highlight the importance of the range of generated noise in different traffic conditions.

The article entitled "Integrating Bus Holding Control Strategies and Schedule Recovery: Simulation-Based Comparison and Recommendation" presents an examination of the effect of bus drivers behavior on bus holding control strategies and more specifically their effort in catching up with schedule in case of delay, i.e., schedule recovery. Based on the analysis and proposed solution, research study shows outcomes providing an insight into the bus stop layout design and implementation of holding methods in the context of cruising guidance.

The editorial team hopes that this particular special issue will be interesting for the great variety of readers and help them in terms of their scientific and research activities to make progress in implementing and developing the sustainable transport and mobility.

\section{Conflicts of Interest}

The guest editors declare that there are no conflicts of interest regarding the publication of this article.

\section{Acknowledgments}

Last but not least, the editorial team would like to thank all the reviewers for the time they spent to evaluate presented articles, and is even more grateful for their constructive comments, remarks, and suggestions for authors in order to revise and modify their articles. After all, all of it has helped to publish these research works.

Ondrej Stopka Vladislav Zitricky Borna Abramovic Marin Marinov Stefano Ricci 


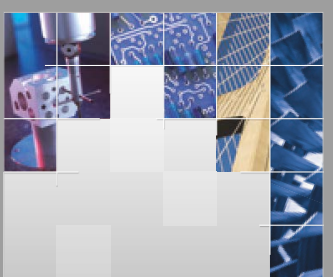

\section{Enfincering}
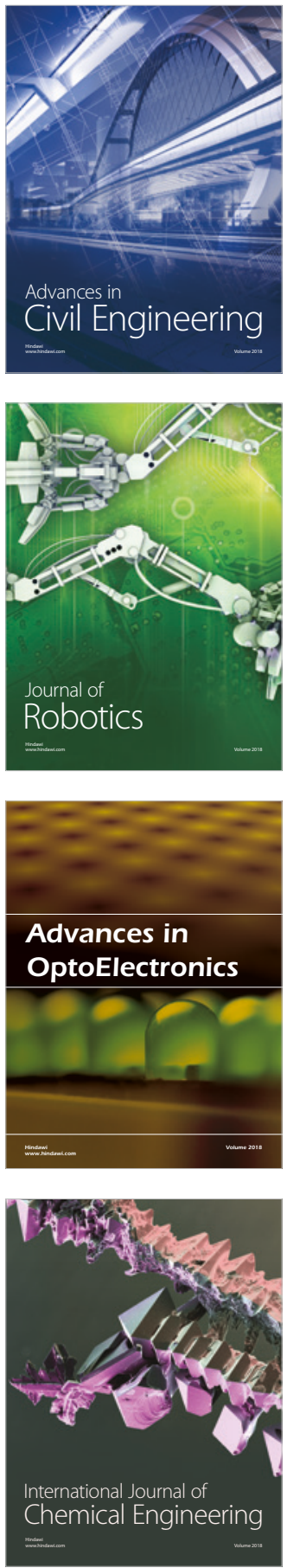

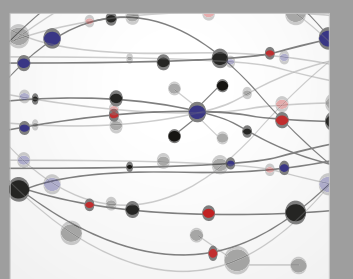

\section{Rotating \\ Machinery}

The Scientific World Journal

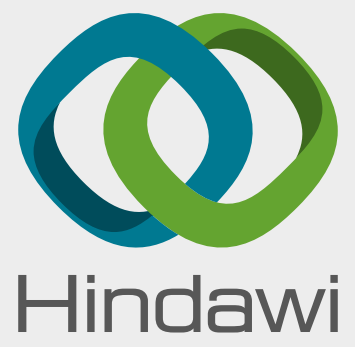

Submit your manuscripts at

www.hindawi.com
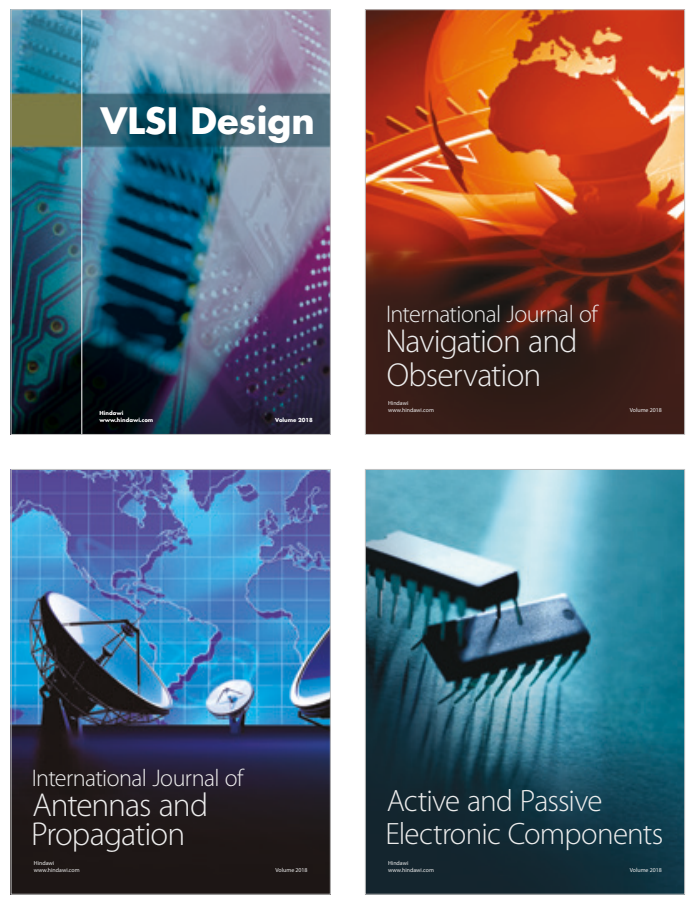
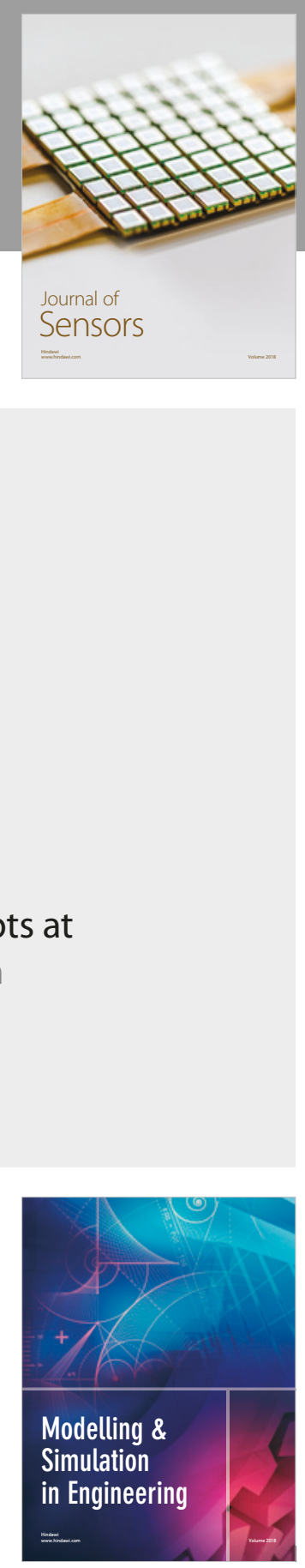

\section{Advances \\ Multimedia}
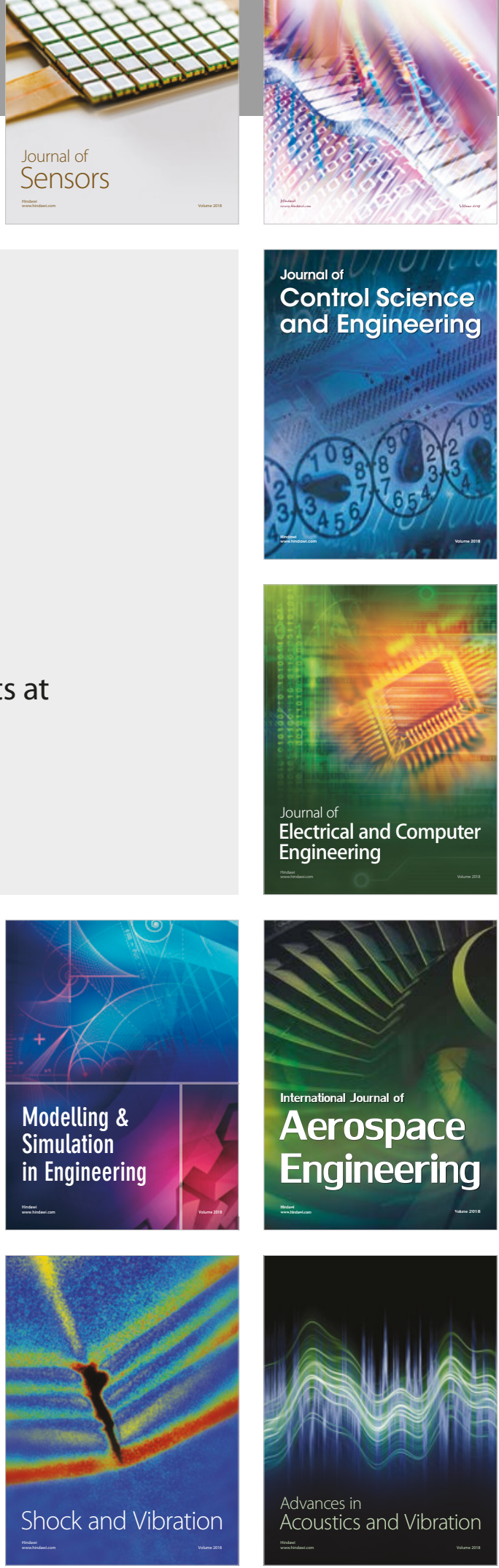